\title{
3D-integrated all-solid-state batteries
}

— Peter H.L. Notten - Email: p.h.l.notten@tue.nl - DOI: 10.1051/epn/2011303

E Eindhoven University of Technology - Interfacultary group Energy Materials and Devices - Department of Chemical Engineering and Chemistry and Department of Electrical Engineering - Den Dolech 2, 5600 MB Eindhoven, The Netherlands

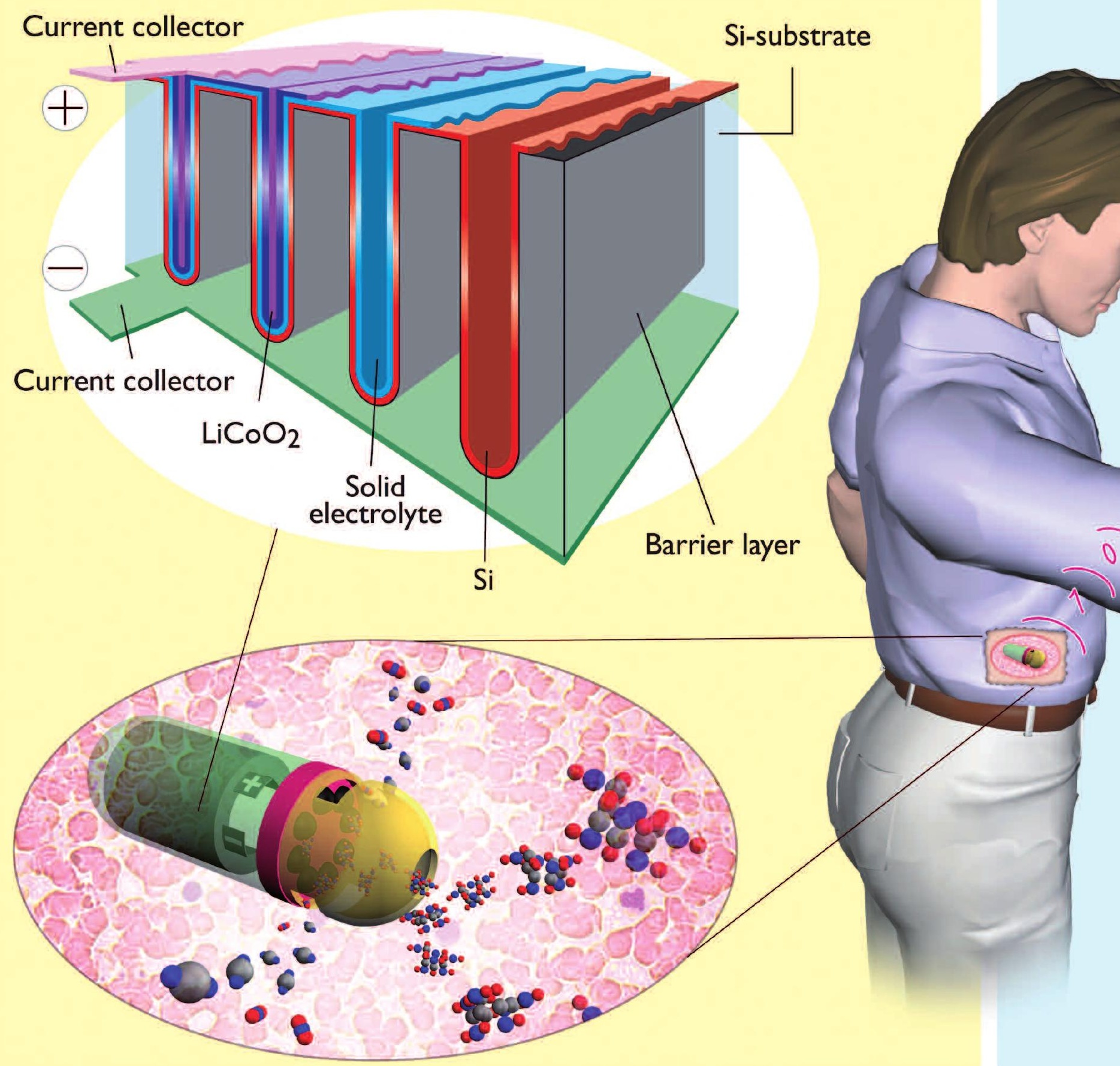




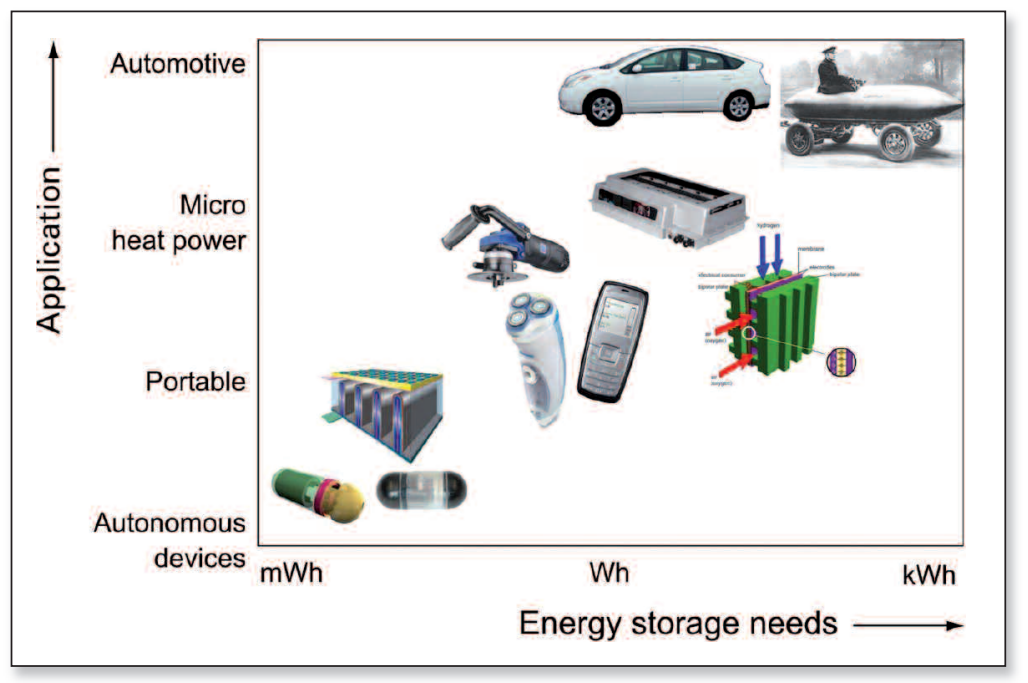

these from individual components, whilst the share of inactive overhead material, e.g. the package, increases significantly. This leads to on-chip integration of sensor and controller. As the energy consumption will be small, this opens up the further possibility to also integrate the battery. Here, allsolid-state batteries are preferred as this excludes the risk of liquid electrolyte leakage.

Electricity can be stored effectively in either capacitors or batteries. In capacitors, charge carriers are physically accumulating at the electrode/dielectric interface. Since the energy stored in capacitors is proportional to the interface area, one way to increase the amount of charge is to enlarge the active surface area. More efficient storage of electrical energy can be achieved in batteries,

A FIG. 1: In the near future, rechargeable batteries will power

a wide variety of electronic applications. This will range from electrical vehicles, to micro

co-generation units, to portable consumer

electronics, to small-sized autonomous wireless devices, each characterized by its energy storage needs.

- FIG. 2: (a)

Communication inside our future offices and houses by means of wireless sensor nodes creating ambient intelligence (see text). The inset at the upper left side shows in somewhat more detail the various func

tions of these

wireless sensors. (b) Examples illustrating integrated all-solid-state batteries in future medical applications,

including

implants for nerve/muscle stimulation and drug delivery by implanted electronic pills.

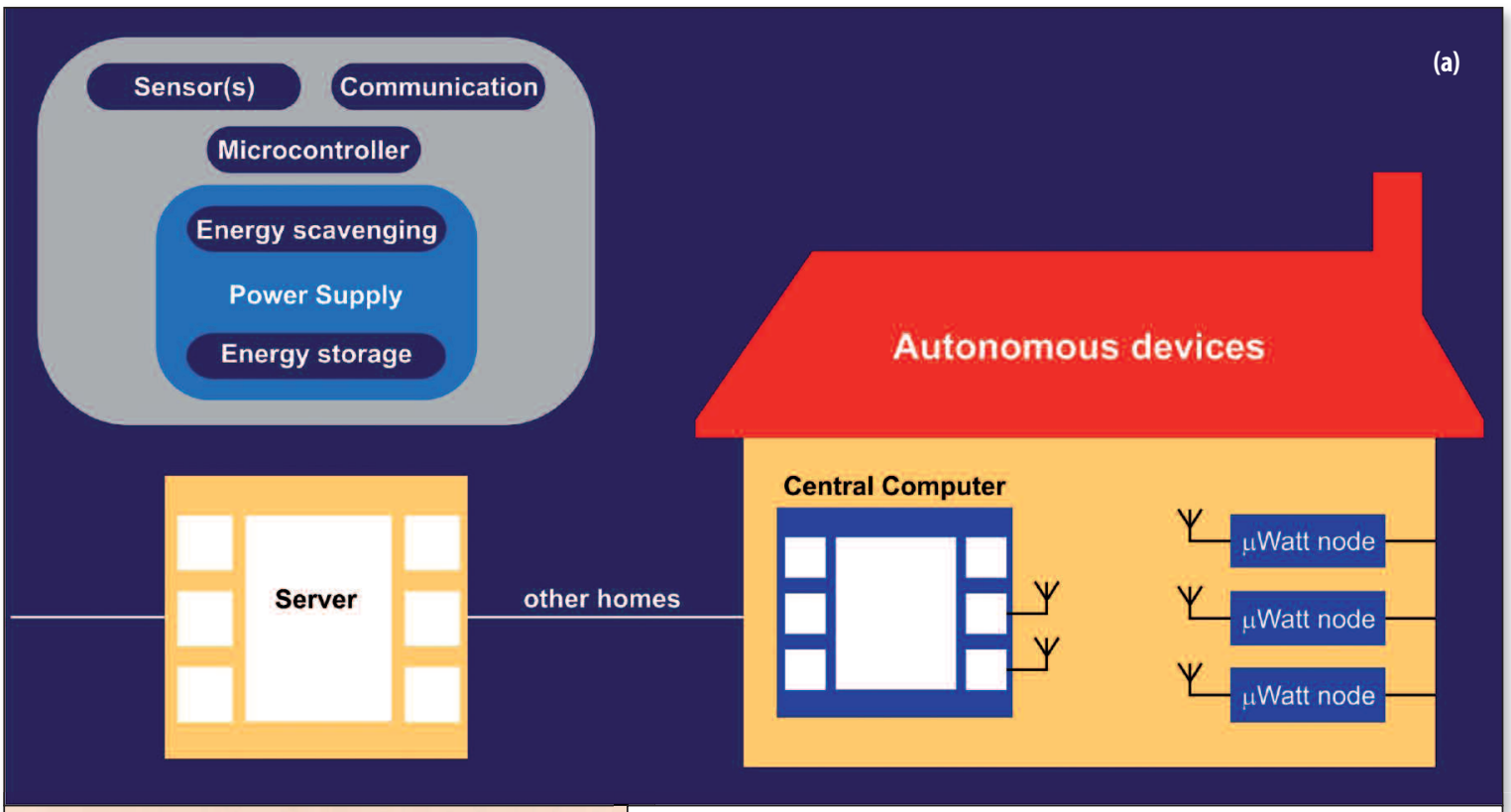

(b)
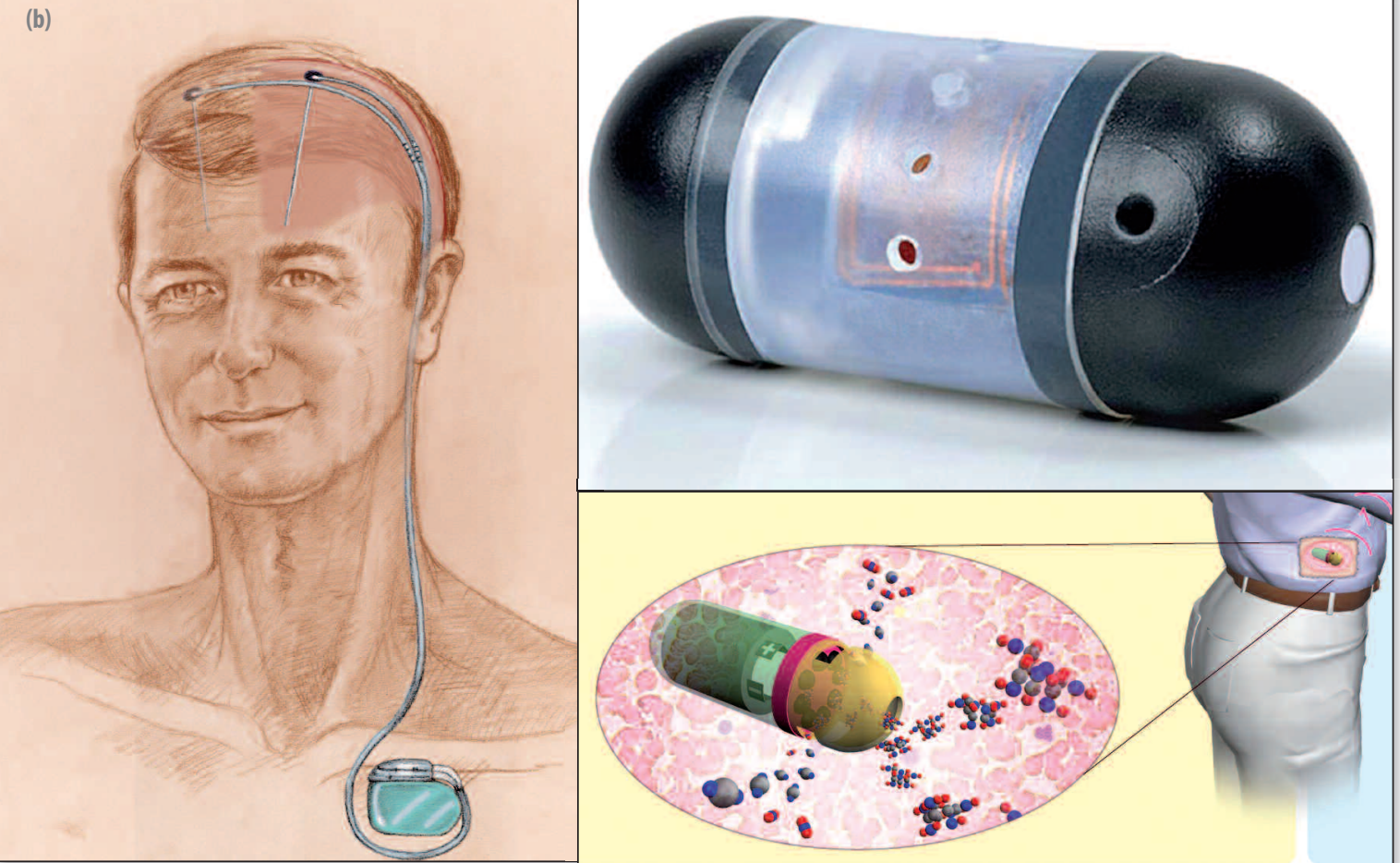
because electrons not only accumulate at the electrode/electrolyte interface, but also are converted into chemical energy, which subsequently is stored inside the battery electrodes. This results in at least a four orders of magnitude increase of the energy density in batteries in comparison with capacitors [4].

Unfortunately, the energy density of existing planar allsolid-state batteries is rather poor considering the energy demand of many autonomous devices. These planar systems are based on metallic lithium serving as anode with $\mathrm{N}$-doped $\mathrm{Li}_{3}(\mathrm{PO})_{4}$ (LiPON) serving as solid-state electrolyte [6]. The use of the extremely reactive metallic lithium requires an expensive packaging technology. Moreover, pure lithium is highly volatile and melts at about $181^{\circ} \mathrm{C}$, a temperature lower than the soldering temperature usually applied in the electronic industry. Therefore, it would be an advantage to make use of the more stable, so-called intercalation materials, which can store lithium safely at high energy density inside the electrodes. Several new concepts have been proposed all based on 3D-batteries, making use of the combined effect of intercalation materials and surface area enlargement [7]. One of these methods exploits modern IC-technology and makes use of the excellent storage capabilities of thin film silicon anodes, as will be highlighted below.

\section{Electrochemical storage of Lithium in Silicon}

Silicon is an excellent intercalation material for lithium. According to the phase diagram approximately four lithium atoms can be stored per silicon atom, making this electrode material extremely high energy dense. As a consequence of the high lithium content, the volume expansion is also extraordinary, inducing repeated decrepitation of silicon upon lithium during storage and release [4]. This causes severe contact problems inside the electrode and hence a poor cycle life.

It has, however, been shown that thin films of silicon are mechanically much more stable, because the lattice expansion only takes place normal to the surface [8]. In order to study such thin-film electrodes electrochemically, a silicon wafer has been fully covered with a $70 \mathrm{~nm}$ thick TiN barrier layer followed by a well-defined surface area of $60 \mathrm{~nm}$ thick poly-silicon, acting as anode, see top-view in Figure 3a. A cross-section of such configuration is shown in Figure 3b. TiN serves both as electronic conducting material and as ionic barrier for lithium ions, preventing lithium from diffusing into the silicon substrate [9] The amount of active silicon in the thin film has accurately been quantified by Rutherford Backscattering Spectrometry (RBS) [5].

Figure $3 \mathrm{c}$ shows the lithium storage performance of a silicon thin-film electrode when applying a constant current $I$. The silicon electrode voltage $E$ has been measured with respect to a metallic lithium reference electrode and the amount of charge $Q=\int I \cdot d t$ is plotted on the abscissa. Several intercalation stages can be distinguished in the voltage curve, corresponding to various nano-crystalline phase transitions. Applying different currents and plotting these as a function of the electrode potential, a semi-logarithmic dependence is to be expected, in line with general electrochemical rate laws for charge transfer reactions [5]. Deviation from this linear behaviour beyond $\ln (\mathrm{A})=-8$, i.e., (dis)charging in less than 10 minutes, is due to lithium diffusion limitations inside the silicon electrode. The life cycle performance was found
V FIG. 3:Top view (a) and cross-section (b) of a silicon thin film $(60 \mathrm{~nm})$ electrode

deposited by LowPressure Chemical Vapor Deposition on a $70 \mathrm{~nm}$ thick TiN barrier layer, deposited by Atomic Layer Deposition. Graphs of the electrode voltage $E$ vs. stored charge $Q(c)$ show that silicon has a much higher reversible storage capacity than graphite, which nowadays is the standard anode material in almost all conventional Li-ion batteries. The inset shows that the charge transfer reaction is rate-determining up to high currents. At higher currents deviation from this straight line indicates that ionic transport of lithium ions in these thin films start to play a role. Reproduced with permission from Wiley [5]

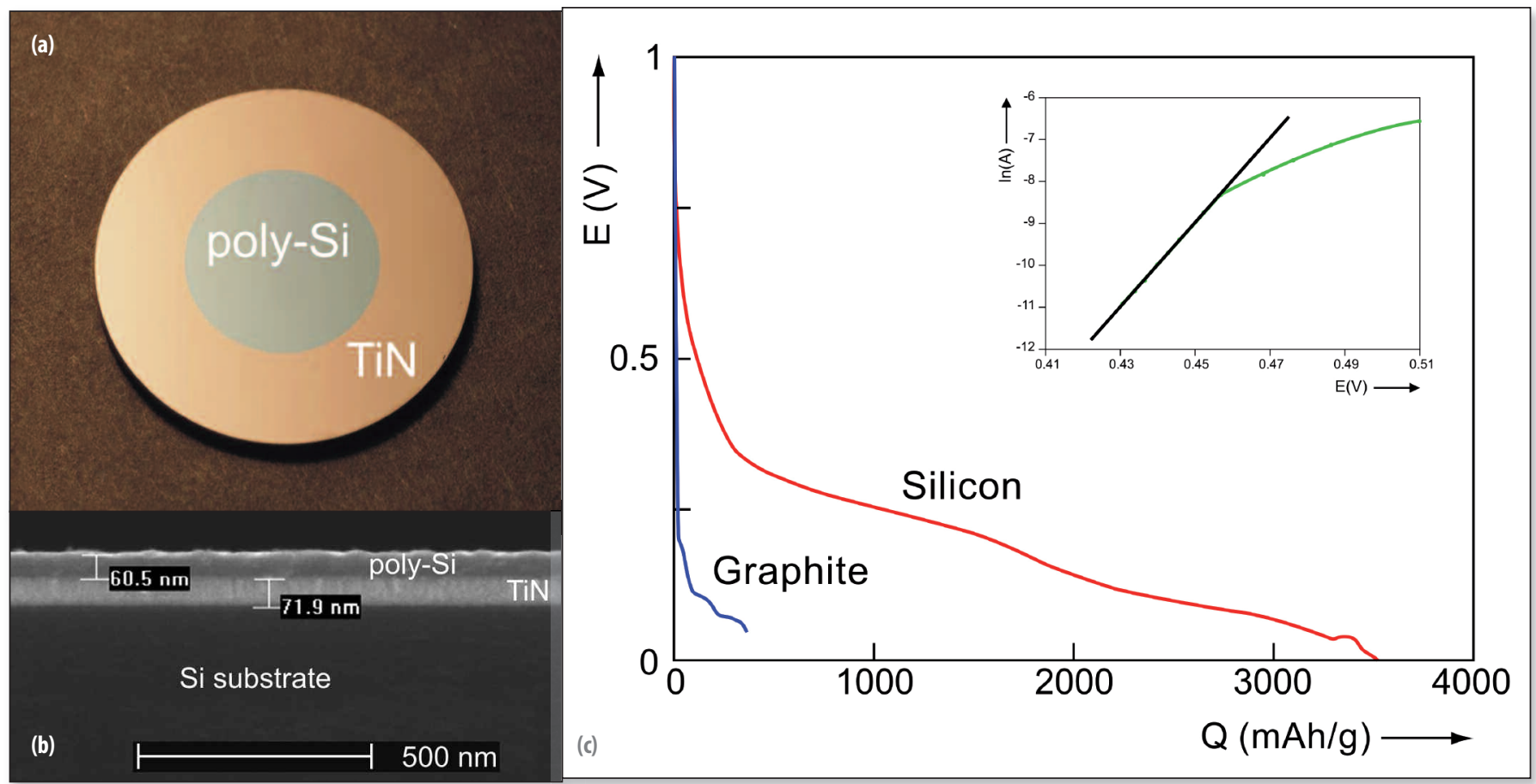




\footnotetext{
> FIG. 4:

3D-integrated

all-solid-state

battery for

powering

autonomous

devices. (a) The

various layers

indicated are

deposited in

high-aspect-ratio

trenches etched

in, for example,

silicon. (b) The

geometry of the

structure is char-

acterized by

footprint dimen-

sions ( $L$ and $h$ ),

trench height $(h)$

and width (w)

and the spacing

between succes-

sive trenches $(\mathrm{s})$.

(c) and (d)

Autonomous

power supply

unit consisting of

3D-integrated

all-solid-state

lithium-ion bat-

teries combined

with electricity

generating

devices, such as a photovoltaic cell

(c) and a bioinspired fuel cell (d). Reproduced with permission from Wiley $[4,10]$.
}

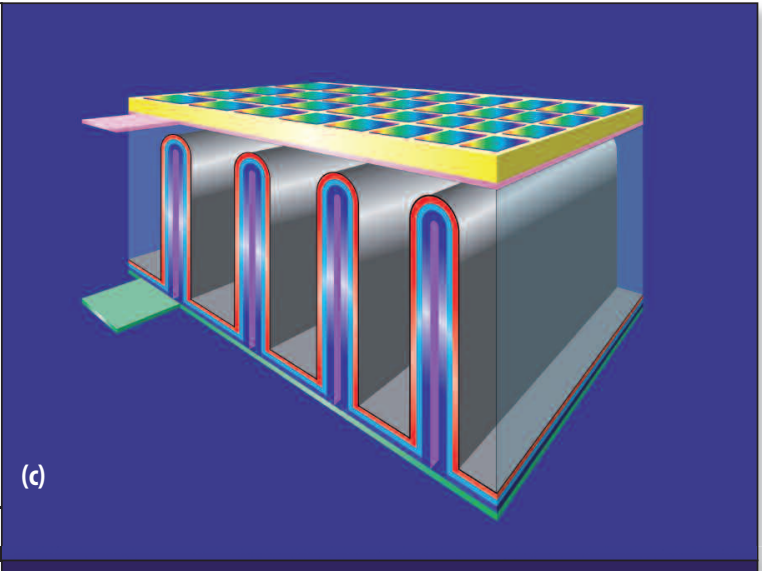

Integrated Energy System

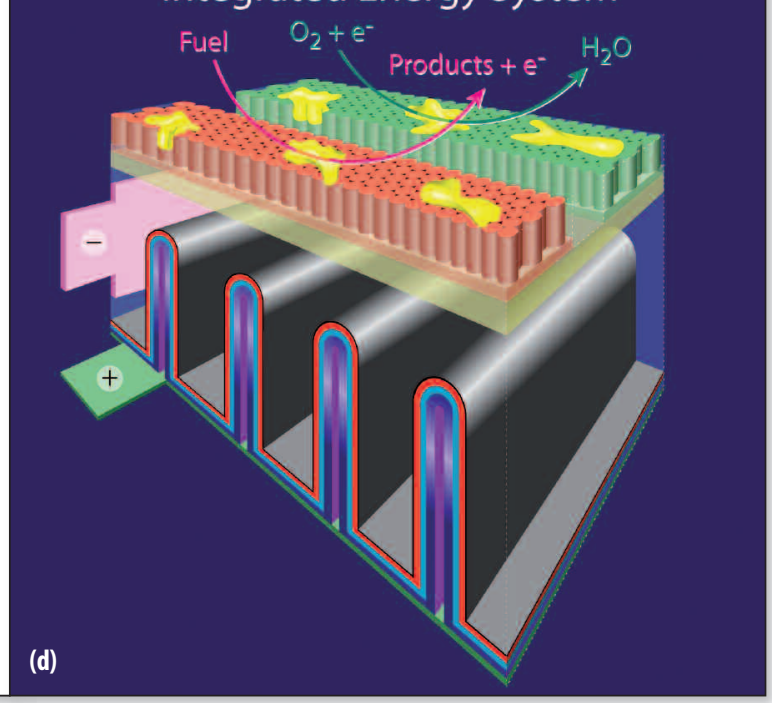

(d) to be excellent with the silicon electrode covered by solid-state electrolyte, showing hardly any degradation, thus making these electrodes suitable for long life application [4].

The most striking aspect, however, is the extremely high energy density compared with graphite electrodes used in conventional Li-ion batteries as anode material. Only $372 \mathrm{mAh} / \mathrm{g}$ can be stored reversibly in graphite compared with $\sim 3500 \mathrm{mAh} / \mathrm{g}$ in silicon. This truly is an impressive improvement in energy density and, together with the long cycle-life, makes it an attractive system to be implemented in 3-D integrated all-solidstate batteries.

\section{D-integrated all-solid-state battery concept}

All-solid-state integrated batteries consist of thin-film barrier layers covering anisotropically etched singlecrystal silicon, yielding a large surface area substrate as is illustrated in Figure 4a. Subsequently, various active battery layers are deposited homogeneously inside this structured substrate, starting with a thin film Si-anode, a solid-state electrolyte and a thin film acting as cathode (e.g., $\mathrm{LiCoO}_{2}$ ). In order to match the lithium capacity of both electrodes, the cathode should be about 20 times thicker than the Si-anode. Deposition of a second current collector completes the 3D-battery integration. Defining the dimensions of the 3D-trench structure (Figure $4 \mathrm{~b}$ ) by width $(w)$, height $(h)$ and spacing between trenches $(s)$ plus the characteristics of the electrode and electrolyte materials, the surface area enlargement $(A)$ can be calculated according to

$$
A=l+2 h \frac{L-s}{L(w+s)}
$$

where $L$ and $l$ represents the footprint dimensions.

Using standard etching technology, an area enlargement of 25 can easily be achieved [5]. Such surface area enlargement combined with the energy densities of the active materials, result in 3D-integrated batteries with energy density of $\sim 1.5 \mathrm{mAh} \cdot \mu \mathrm{m}^{-1} \mathrm{~cm}^{-2}$ footprint area. With an operating voltage of about $3.5 \mathrm{~V}$, a single-sided device is therefore expected to store $\sim 5 \mathrm{mWh} \cdot \mu \mathrm{m}^{-1} \mathrm{~cm}^{-2}$. Obviously, a double-sided process will further increase these numbers. Some experimental results towards 3Dintegrated batteries are shown in Figure 5, including Reactive Ion Etched trenches (a) and holes (b). Using Chemical Vapor Deposition and/or Atomic Layer Deposition various active layers have been step-conformal deposited, examples of which are 3D-Si anodes (c) and $3 \mathrm{D}-\mathrm{LiCoO}_{2}$ cathodes (d) [10]. 


\section{Outlook}

A new 3D-integrated all-solid-state battery concept has been presented [4,5] This concept is based on the step-conformal deposition of various (in)active layers on a high surface area silicon substrates obtained by micro-etching. Due to the large surface area enhancement, the proposed battery concept will improve the storage capacity of future 3D-integrated all-solid-state Li-ion micro-batteries significantly and offers interesting integration options. In future, fully autonomous power supply units can be designed by combining this battery concept with an electricity-generating device. In case of light being available, a solar cell combination is very effective (Fig. 4c). When light is lacking, as is the case for medical implants, an integrated bio-inspired fuel-cell running on glucose may be employed (Fig. 4d). Recently, a mathematical model has been developed that simulates the power and energy performance of these 3D-integrated all-solid-state devices in their various applications [11].

\section{Acknowledgements}

The author would like to acknowledge all co-workers for their valuable contributions during the years in both the experimental and theoretical development of the 3Dintegrated battery concept. Frans Schraven and Henny Herps are acknowledged for making the drawings.

\section{About the Author}

Peter H.L. Notten was born in The Netherlands in 1952 , was educated in analytical chemistry and joined the Philips Research laboratories from 1975 to 2010.
While working at these laboratories he received his $\mathrm{PhD}$ from the Eindhoven University of Technology (TU/e) in 1989. Since 2000 he has been appointed as part-time professor at the Eindhoven University of Technology. In 2010 he obtained a permanent position at TU/e where he now is heading the group Energy Materials and Devices.

\section{References}

[1] M. Armand and J.-M. Tarascon, Nature 451 (2008) 652-657.

[2] R.A.H. Niessen and P.H.L. Notten, Electrochem. Solid-State Lett. 8 (2005) A534-A538.

[3] P.J. Bouwman, B.A. Boukamp, H.J.M. Bouwmeester and P.H.L. Notten, J. Electrochem. Soc. 149 (2002) A699-A709.

[4] P.H.L. Notten, F. Roozeboom , R.A.H. Niessen and L. Baggetto, Adv. Mat. 19 (2007) 4564.

[5] L. Baggetto, R.A.H. Niessen, F. Roozeboom and P.H.L. Notten, Adv. Funct. Mat. 18 (2008) 1-10.

[6] J.B. Bates, N.J. Dudney, D.C. Lubben, G.R. Gruzalski, B.S. Kwak, Xiaohua Yu, R.A. Zuhr, J. Power Sources 54 (1995) 58.

[7] J.F.M. Oudenhoven, L. Baggetto and P.H.L. Notten, Adv. Energy Mat. 1 (2011) 10

[8] T. Takamura, S. Ohara, M. Uehara, J. Suzuki and K. Sekine, J. Power Sources 129 (2004) 96.

[9] H.C.M. Knoops, L. Baggetto, E. Langereis, M.C.M. van de Sanden, J.H. Klootwijk, F. Roozeboom, R.A.H. Niessen, P.H.L. Notten and W.M.M. Kessels, J. Electrochem. Soc. 155 (2008) G287-G294.

[10] J.F.M. Oudenhoven, T. van Dongen, R.A.H. Niessen, M.H.J.M de Croon and P.H.L. Notten, J. Electrochem. Soc. 156 (2009) D169-D174.

[11] D. Danilov, R. Niessen and P.H.L. Notten, J. Electrochem. Soc 158, A215 (2011).
V FIG. 5:

High-aspect-ratio etching of trenches (a) and pores (b) in mono-crystalline silicon. Highaspect-ratio deposition of a $60 \mathrm{~nm}$ silicon anode thin film on top of a $70 \mathrm{~nm}$ TiN barrier layer (c) and $500 \mathrm{~nm}$ thick LiCOO cathode thin film (d) inside trenches [10]

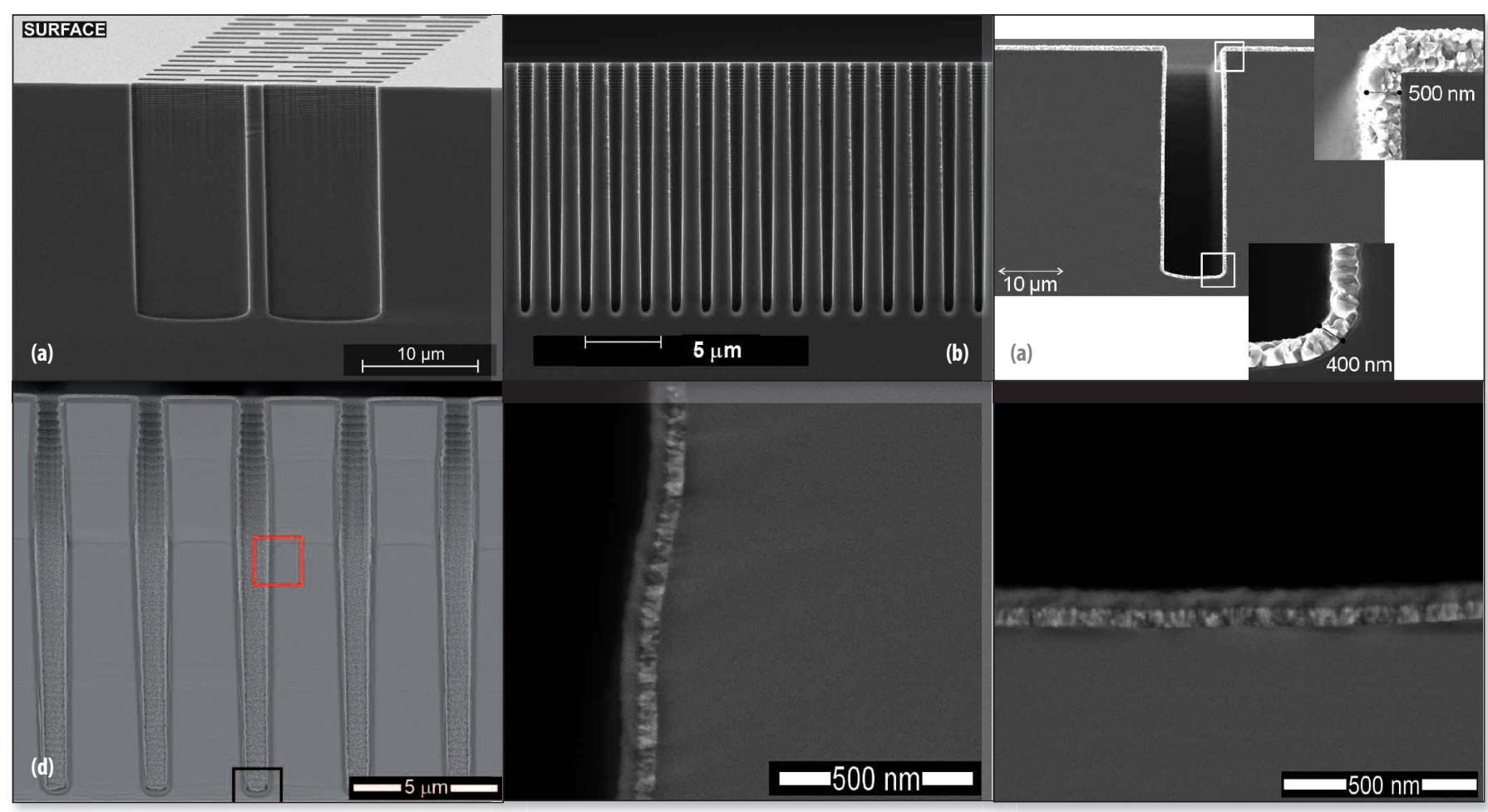

